\title{
PReS-FINAL-2062: The need for conducting different rehabilitation complexes for patients with juvenile idiopathic arthritis (JIA)
}

\author{
TA Shelepina, IP Nikishina* \\ From 20th Pediatric Rheumatology European Society (PReS) Congress \\ Ljubljana, Slovenia. 25-29 September 2013
}

\section{Introduction}

We have developed and implemented rehabilitation complexes. A corrective complex - for disabled patients with severe functional restrictions, causing social constraints. A mobilization complex - for patients with moderate functional restrictions that do not cause social constraints. A health-improving complex - for functionally intact patients with no functional restrictions.

\section{Objectives}

to compare the need for such complexes in patients, who were in hospital in 2007, 2008 and 2012.

\section{Methods}

Children's ward patients suffering from various forms of JIA, aged two to eighteen years, who were in the hospital in 2007, 2008 and 2012 and underwent rehabilitation treatment; over $50 \%$ of the patients were re-hospitalized within a specified time. We compared the need for conducting different rehabilitation treatment complexes in patients treated in 2007, 2008 and 2012.

\section{Results}

See Table 1.

\section{Conclusion}

A statistically significant increase was detected in the number of functionally intact patients among the patients undergoing rehabilitation treatment in 2012, compared with those undergoing treatment in 2007, and in 2008, thanks to the practical introduction of biologic

Pediatric Rheumatology, Scientific Research Institute of Rheumatology, Moscow, Russian Federation 